\title{
Impactos de depreciações cambiais no hiato do produto brasileiro
}

\author{
Maurício Benedeti Rosa \\ Mestre em Economia Aplicada - Universidade Federal de São Carlos (UFSCar) \\ E-mail:mbr_15@hotmail.com \\ Diego Sarti de Souza \\ Mestre em Economia Aplicada - Universidade Federal de São Carlos (UFSCar) \\ E-mail:diego.sarti@gmail.com \\ Maria Aparecida Silva Oliveira \\ Doutora em Economia - Docente da Universidade Federal de São Carlos (UFSCar) \\ E-mail: aparecidaoliveira@ufscar.br
}

Resumo: Este trabalho analisou os efeitos de depreciações cambiais, além das políticas fiscal e monetária, sobre o hiato de produto brasileiro através do modelo de Vetor Autorregressivo (VAR). Os resultados obtidos, expressos em elasticidades, mostraram que depreciações cambiais de $1 \%$ elevam discretamente o hiato do produto em $0,05 \%$, magnitude inferior aos impactos dos choques nos gastos públicos e na taxa de juros, minimizando o papel da política cambial no curto prazo. Por fim, a decomposição da variância indicou como principais determinantes do hiato do produto a relação dívida/PIB, além dele próprio, os quais somados atingem mais de 90\% em 12 períodos. Palavras-chave: Taxa de câmbio; hiato do produto; modelo de vetor autoregressivo.

Abstract: This paper assessed the impact of exchange rate depreciation, fiscal and monetary policies, on the output gap of Brazilian economy using the Vector autoregressive (VAR) model. Expressed in elasticities, results showed that exchange rate shocks of $1 \%$ raise the output gap only by 0,05\%, less than the impact of shocks on public spending and interest rates, minimizing the role of exchange rate policy in the short term. Additionally, variance decomposition indicated the main determinants of output gap as the debt-to-GDP ratio and the output gap itself, which combined reach more than $90 \%$ at the end of 12 periods.

Key words: Exchange rate; output gap; vector autoregressive model.

JEL Code: F31; F41. 


\section{INTRODUÇÃO}

O estudo das políticas cambiais associado aos seus efeitos no crescimento econômico é de extrema importância para países em desenvolvimento, tal qual o Brasil. A depreciação do câmbio estimula o crescimento das exportações líquidas, levando em conta a expectativa de aumento da demanda agregada e, consequentemente, o aumento da produção interna. Por outro lado, depreciar a moeda doméstica encarece insumos importados necessários à indústria nacional, o que implica em custos extras, inflação e, especialmente sob o regime de metas de inflação, juros mais elevados, com consequente efeito negativo na produção. A expansão ou contração da economia depende então da magnitude dos efeitos mencionados, ou seja, a depreciação cambial pode ter efeitos ambíguos (expansionistas e contracionistas) na economia, dependendo ainda do horizonte de tempo a ser considerado.

A desvalorização cambial pode ser considerada uma das medidas mais traumáticas de política econômica, ao passo que governos relutam em adotá-la. Quando um país tem custos financeiros que não the permitem balancear pagamentos internacionais ao nível de atividade econômica corrente, uma alternativa recomendada é a desvalorização da moeda, à qual se atribui a capacidade de diminuir preços e custos domésticos medidos em moeda estrangeira que antes eram financiados com déficits em sua reserva. Os países em desenvolvimento respondem pela maior parte dos episódios de desvalorização cambial ${ }^{1}$, sendo que os motivos usuais para sua adoção incluem pressões de instituições financeiras internacionais, promoção da industrialização, melhora dos termos de troca, elevação de receitas para redistribuição de renda, dentre outros (COOPER, 1971).

O Brasil se caracteriza por não permitir que sua política cambial seja um entrave ao crescimento econômico (DORNBUSCH et al., 1995), o que sugere maior volatilidade nos níveis da taxa de câmbio e resulta em episódios frequentes de desvalorização cambial, como os destacados por Frankel e Rose (1996), ocorridos nos anos de 1979, 1983, 1987 e 1992. Além dessas, ocorridas até o início dos anos 1990, nova

\footnotetext{
${ }^{1}$ A extensão dos episódios de desvalorização cambial em países em desenvolvimento é ilustrada em Frankel e Rose (1996), os quais trabalham com 117 episódios de desvalorização em mercados emergentes entre 1971 e 1992.
} 
p. 61 - Impactos de depreciações cambiais no hiato do produto brasileiro

desvalorização da moeda brasileira ocorreu em 1999 como consequência de desequilíbrios cambiais e fiscais e da falta de confiança na capacidade do governo em sustentar sua política econômica, na qual houve o abandono do regime de câmbio fixo para adoção do regime de câmbio flutuante (DE PAULA e ALVES JR., 2000; SCHWARTSMAN, 1999). Ao final de 2002, com as expectativas negativas relacionadas à eleição de Lula, um novo episódio de depreciação cambial foi observado. Movimentos semelhantes ocorreram no segundo semestre de 2008, fruto da crise financeira internacional, de forma mais branda entre 2012 e 2015 (NASSIF, FEIJÓ e ARAÚJO, 2015), e de forma acentuada a partir de 2018.

As recentes experiências internacionais têm mostrado que economias emergentes que apresentam taxas de câmbio flutuantes e mobilidade perfeita de capitais interveem sobre a taxa de câmbio de modo a reduzir sua volatilidade. Como muitas economias emergentes têm especificidades tais como alta volatilidade dos fluxos de capital, além de déficits persistentes em conta corrente, as operações dos seus regimes cambiais flutuantes estão associadas à alta volatilidade na taxa nominal de câmbio, levando-as a sistemáticas intervenções nesse respectivo mercado (NASSIF, FEIJÓ e ARAÚJO, 2015).

Considerando a relevância da política cambial no cenário macroeconômico brasileiro, trabalhos que avaliam os impactos de curto prazo de uma depreciação cambial no desempenho da economia ainda são incipientes na literatura. Não obstante, o aumento nas taxas de inflação decorrentes da depreciação cambial tem relação muito próxima à necessidade de elevação das taxas de juros nos regimes de metas de inflação, efeito esse que parece subdimensionado nos trabalhos relacionados. Dessa forma, o presente artigo objetiva utilizar o modelo IS-MP-IA, desenvolvido por Romer (2000) e estendido por Hsing (2005) para avaliar, num horizonte de curto prazo, qual é o efeito de depreciações cambiais no hiato do produto brasileiro, do quarto trimestre de 2001 ao primeiro trimestre de $2018^{2}$.

\footnotetext{
2 Utilizam-se como critérios para a escolha do período a disponibilidade de dados e o princípio da parcimônia na utilização de dummies em séries temporais, a fim de filtrar o efeito determinístico de crises (e.g. crises políticas e a crise financeira de 2008). A história recente do país esta repleta destes efeitos, os quais podem ferir o princípio da parcimônia (exigindo mais dummies), além de distorcer os resultados.
} 
Este trabalho está dividido em cinco seções complementares a esta sucinta introdução. A seção 2 traz uma revisão de literatura, a seção 3 ilustra o modelo teórico IS-MP-IA, a seção 4 detalha a modelagem econométrica, enquanto que as seções 5 e 6 apresentam resultados e conclusões, respectivamente.

\section{REVISÃO DE LITERATURA}

Existe vasta literatura relacionada aos efeitos de depreciações cambiais sobre o crescimento econômico, a qual varia principalmente quanto ao tipo de modelo teórico utilizado, caracterizados pelos crescimentos puxados pela oferta ou pela demanda ou ainda por ambas, além de diferenças quanto à metodologia empírica empregada e as variáveis utilizadas. Assim, diferenças no arcabouço teórico, nos métodos econométricos, bem como nas variáveis explicativas consideradas como importantes impactam as conclusões de cada trabalho, as quais podem divergir mesmo quando uma mesma realidade é analisada.

Parcela significativa da literatura evidencia os efeitos contracionistas de desvalorizações cambiais (KAMIN e ROGERS, 2000), sendo um de seus principais efeitos a redistribuição de renda de trabalhadores (wage-owners) para empresários (profitowners). Considerando a existência de certa rigidez de salários no curto prazo, o aumento no preço de bens domésticos diminui os salários reais, além de elevar a receita do setor exportador, em moeda doméstica, e, consequentemente, o lucro dos empresários (KRUGMAN e TAYLOR, 1978).

No âmbito do comércio, o efeito contracionista da desvalorização cambial pode ser tanto maior quanto for o déficit inicial na balança comercial, pois, em decorrência do aumento de preços dos bens importados e exportados, o efeito líquido de ambos acarretará em reduções da renda real doméstica e posterior diminuição da demanda agregada (COOPER, 1971; KRUGMAN e TAYLOR, 1978). O viés contracionista também pode se relacionar com o aumento do custo de capital em consequência da elevação de juros domésticos (LIZONDO e MONTIEL, 1989), com a possibilidade de antecipação ou surpresa de um choque cambial (AGÉNOR, 1991; COOPER, 1971), com as magnitudes 
p. 63 - Impactos de depreciações cambiais no hiato do produto brasileiro

das elasticidades-preço de exportações e importações (EDWARDS, 1986), dentre outros.

Krugman e Taylor (1978) desenvolveram um modelo teórico simples a fim de ilustrar efeitos contracionistas da desvalorização cambial. De maneira contrária à literatura tradicional, na qual a demanda doméstica é estimulada tanto pela elevação do consumo de bens domésticos, que ficam mais baratos em relação a importados, quanto pelo incentivo às exportações, os autores mencionam como contracionistas, considerando a balança comercial inicialmente em déficit, a elevação de preços de bens comercializáveis e a consequente redução da renda real doméstica, a qual tem impacto negativo sobre a demanda agregada. De forma complementar, segundo Lizondo e Montiel (1989), desvalorizações cambiais provocam aumento da demanda por bens não comercializáveis e diminuição da demanda por produtos importados, redução de saldos reais e elevação dos custos de capital e de insumos importados, além de impactos recessivos frutos de elevações da taxa de juros para lidar com inflação. Setores exportadores devem crescer, enquanto que o aumento do salário nominal provavelmente freie investimentos no setor doméstico, gerando ambiguidade nos efeitos da desvalorização cambial.

Hsing (2005) estendeu o modelo IS-MP-IA (ROMER, 2000) para avaliar como determinadas variáveis macroeconômicas e financeiras, dentre elas a taxa real de câmbio, impactam o PIB de equilíbrio da Alemanha no curto prazo. No arcabouço teórico do modelo, espera-se que a depreciação cambial estimule as exportações e eleve a demanda agregada, mas, por outro lado, aumente as taxas de inflação e juros e reduza a oferta agregada, de forma que o efeito total é ambíguo. O autor conclui que a relação entre a apreciação cambial e o produto de equilíbrio é positiva para a Alemanha, sendo que uma apreciação cambial de $1 \%$ gera um crescimento de $0,688 \%$ no produto de equilíbrio.

No Brasil, o debate entre políticas cambiais e seus efeitos na atividade econômica continua intenso (GALA e LIBÂNIO, 2008). Enquanto Do Nascimento et al. (2017) confirmaram a influência significativa da taxa de câmbio sobre as decisões por modalidade crédito, Da Silva, Correia e Santolin (2015), através da utilização de um 
modelo macrodinâmico de crescimento com poupança externa, indicaram que apreciações cambiais, embora eficazes no controle da inflação, trazem como consequência negativa a redução na relação entre poupança e investimento.

Baseados no modelo de Bhaduri e Marglin (1990) - considerando a restrição externa e o equilíbrio no balanço de pagamentos como entraves ao crescimento econômico - trabalhos adicionais analisaram os efeitos de depreciações cambiais no crescimento de longo prazo da economia, e caracterizaram-nos como expansionistas.

Segundo Gala e Libânio (2008), assumindo que o setor tradable é maior que o non tradable, e que a apreciação cambial diminui o mark up total do país, o impacto de apreciações cambiais no produto depende da magnitude com que variam consumo e investimento, sendo que este é influenciado por variações nas margens de lucro, e aquele é estimulado com a elevação dos salários reais decorrente da queda dos preços. Os autores concluem que, no longo prazo, câmbios depreciados tendem a estimular a produção de bens comercializáveis com retornos crescentes de escala, externalidades positivas e efeitos de transbordamento.

Em contraste à literatura na qual desvalorizações cambiais geram efeitos expansionistas em países profit-led ${ }^{3}$ e contracionistas nos países wage-led, Missio, Schettini e Jayme Jr (2009) demonstraram ser possível que depreciações sejam expansionistas em países com regime wage-led incluindo ao modelo de Bhaduri e Marglin (1990) efeitos diretos e indiretos da elevação dos lucros sobre o investimento. Por sua vez, Araújo e Gala (2012) passaram a considerar o setor externo e concluíram que com tal modificação o regime de acumulação brasileiro de longo prazo passa de wage-led para profit-led, além de verificarem empiricamente tal resultado utilizando dados trimestrais de 2002 a 2008. Dessa forma, ambos os trabalhos apoiam a depreciação cambial como forma de incentivar a expansão da economia brasileira.

Missio, Oreiro e Jayme Jr (2010), através da associação entre os pensamentos keynesiano e estruturalista latino americano, avaliaram a influência do câmbio na heterogeneidade produtiva e sua relação com o processo de acumulação. Os autores

\footnotetext{
${ }^{3}$ Regimes de crescimento econômico podem ser caracterizados conforme a resposta da demanda agregada às variações na distribuição funcional da renda. Relação positiva entre demanda agregada e maior participação de lucros na renda caracteriza regimes profit-led, enquanto relação negativa caracteriza regimes wage-led (ARAÚJO e GALA, 2012).
} 
p. 65 - Impactos de depreciações cambiais no hiato do produto brasileiro

consideraram investimento como dependente da taxa de câmbio e taxas de acumulação e lucro relacionadas de maneira não linear no modelo de Bhaduri e Marglin (1990), para concluírem que, no longo prazo, o equilíbrio estável acontece com moeda depreciada e alto crescimento, depreciação essa que incentiva gastos em pesquisa e inovação e altera a estrutura produtiva em direção a setores de maior competitividade.

\section{MODELO TEÓRICO}

De acordo com o trabalho de Hsing (2005), baseado em Romer (2000), admitem-se alguns pressupostos para o modelo teórico. O consumo das famílias depende da renda disponível, da taxa real de juros e do preço do mercado de ações. Os investimentos são explicados pela taxa de juros e pelos preços no mercado de ações. As exportações líquidas são influenciadas pela taxa real de câmbio. A política monetária $\mathrm{MP}^{4}$ é determinada pelas diferenças entre a inflação observada e a meta de inflação, pelo hiato do produto $^{5}$, além da taxa nominal de câmbio e da taxa de juros internacional. A inflação observada depende da própria expectativa de inflação, da diferença entre o PIB observado e o potencial e da taxa nominal de câmbio. O modelo pode ser matematicamente descrito conforme as equações (1), (2) e (3).

$Y=C(Y-T, R, S)+I(R, S)+G+N X\left[\left(e\left(P^{f} / P\right)\right]\right.$

$R=R\left(\pi-\pi^{*}, Y-Y^{*}, e, R^{w}\right)$

$\pi=\pi^{e}+\alpha\left(Y-Y^{*}\right)+\beta e$

Descrevendo os termos das equações: da equação (1) tem-se que, $Y$ é o PIB real, $C$ é a função consumo, $T$ é a receita do governo com impostos, $R$ é a taxa real de juros, $S$ é o preço das ações no mercado, I é a função investimento, $G$ são os gastos reais do governo, $N X$ são as exportações reais líquidas, e é a taxa nominal de câmbio, $P^{f}$ o nível de preços no exterior e $P$ o nível de preços no mercado doméstico. O termo $e\left(P^{f} / P\right)$ representa a taxa real de câmbio. Da equação (2) tem-se que a taxa real de juros $R$ depende da diferença entre a inflação medida $\pi$ e a inflação meta $\pi^{*}$, do PIB real $Y$ e do PIB potencial $Y^{*}$, da taxa nominal de câmbio, e da taxa de juros internacional $R^{w}$. Por

\footnotetext{
${ }^{4}$ A equação para a curva MP é consistente com a Regra de Taylor, amplamente utilizada em trabalhos científicos, a qual diz que o banco central deve responder à elevação da taxa de inflação com aumento da taxa de juros nominal mais que proporcionalmente, dessa forma, elevando também a taxa de juros real.

${ }^{5}$ Diferença entre o produto real e o produto potencial.
} 
fim, na equação (3), a inflação $\pi$ depende de sua expectativa $\pi^{e}$, da diferença entre PIB real $Y$ e potencial $Y^{*}$, e da taxa nominal de câmbio.

Solucionando as equações (1), (2) e (3), é possível determinar o PIB da economia na condição de equilíbrio $(\bar{Y})$, conforme equação (4).

$\bar{Y}=\bar{Y}\left[\pi^{e}, G, T, S, e\left(P^{f} / P\right), R^{w} ; \alpha, \beta, \pi^{*}, Y^{*}\right]$

Assim, interpretando-se a equação, pode-se dizer que o PIB de uma economia no equilíbrio $\bar{Y}$ é função da expectativa de inflação $\pi^{e}$, dos gastos do governo $G$, da receita tributária $T$, dos preços do mercado acionário $S$, da taxa real de câmbio $e\left(P^{f} /\right.$ $P$ ), da taxa de juros internacional $R^{w}$, da meta de inflação $\pi^{*}$ e do PIB potencial $Y^{*}$.

Dado o modelo teórico, o objetivo fundamental deste trabalho é analisar empiricamente o impacto de depreciações (choques) cambiais sobre o hiato do produto para o caso brasileiro. Elaborou-se assim um vetor autorregressivo (VAR), onde o hiato do produto é a variável mais endógena, explicada pelas demais variáveis, as quais são descritas na próxima seção.

\section{MODELAGEM ECONOMÉTRICA}

\subsection{Base de Dados}

Os dados referentes à expectativa de inflação e a taxa de juros são da base de dados do Instituto de Pesquisa Econômica Aplicada (IPEA). Por sua vez, PIB real é obtido do Instituto Brasileiro de Geografia e Estatística (IBGE), dados para a dívida líquida do setor público como percentual do PIB (dívida/PIB) são obtidos do Banco Central do Brasil (BCB) e taxa real de câmbio e índice do mercado de ações (Share Price Index) vem da base de dados do Fundo Monetário Internacional (FMI). Todas as variáveis, exceto o PIB real, originalmente eram compostas por observações mensais e foram convertidas para frequência trimestral ${ }^{6}$.

\footnotetext{
${ }^{6}$ Opta-se por utilizar o PIB real com frequência trimestral, e, dessa forma, transformar a periodicidade das demais variáveis, pois as bases de dados alternativas que oferecem o mesmo indicador com frequência mensal utilizam metodologias simples, as quais não incorporam fundamentos econômicos, sendo, portanto, fonte de mais incerteza para a estimativa da variável.
} 
p. 67 - Impactos de depreciações cambiais no hiato do produto brasileiro

A Figura 1 exibe os índices referentes a quatro variáveis explicativas, do último trimestre de 2001 ao primeiro trimestre de 2018: expectativa de inflação, dívida/PIB, taxa real de câmbio e taxa real de juros.

Figura 1 - Expectativa de inflação, dívida/PIB, taxa real de câmbio, e taxa real de juros, do 4T de 2001 ao 1 T de 2018 (2001 T4 = 100).

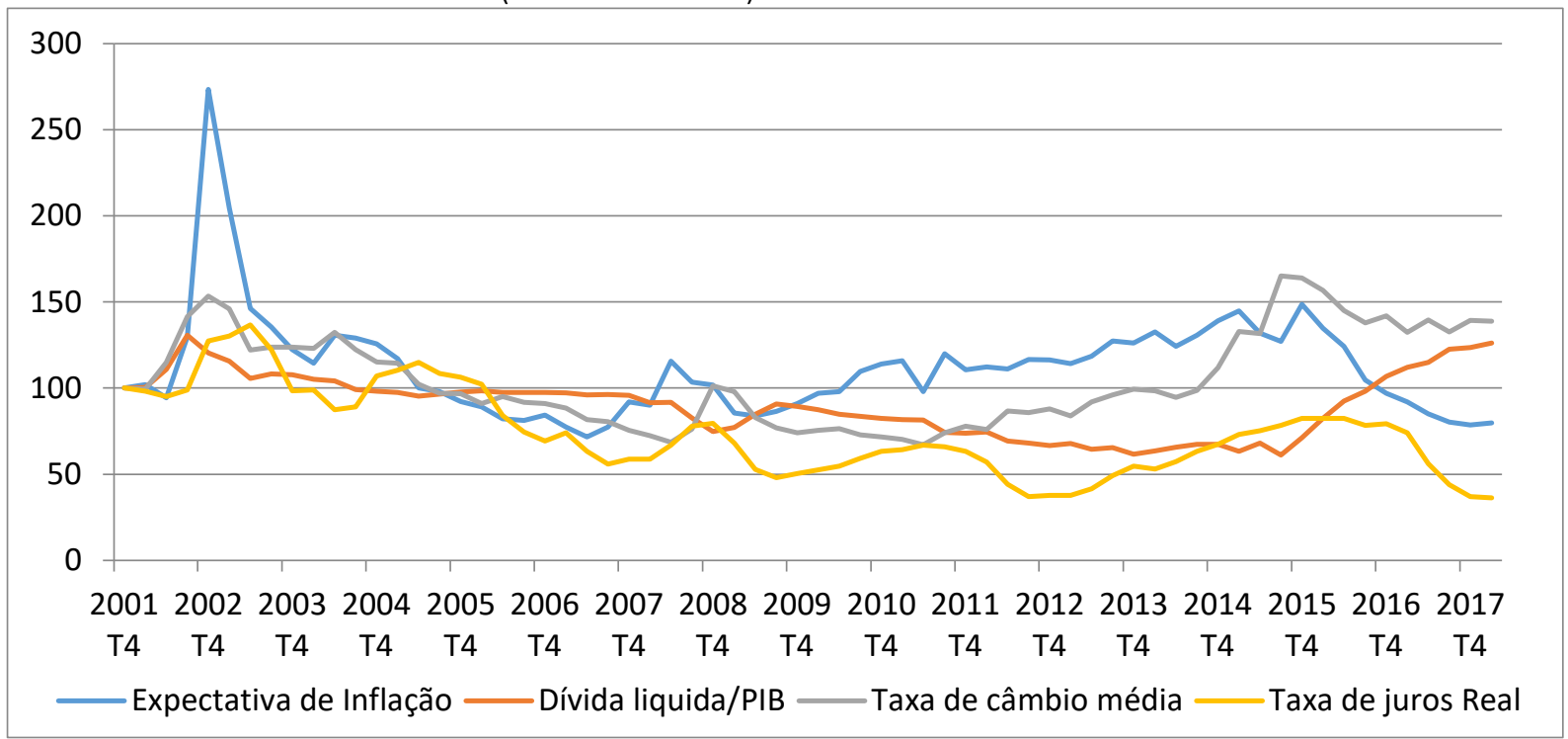

Fonte: Elaboração própria com dados da pesquisa.

De forma geral, variações maiores nas séries apresentadas estão associadas ao ciclo político brasileiro, ou seja, à eleição de Luiz Inácio Lula da Silva em 2002 e a recente crise no governo Dilma Rousseff, além de perturbações no cenário internacional, notadamente a crise financeira internacional de 2008.

Como pode ser observado na Figura 1, o ciclo político tem forte interferência sobre a expectativa de inflação. Em 2002, quando da eleição do presidente Luiz Inácio Lula da Silva, houve um aumento acentuado do índice fruto do temor de um possível não comprometimento do novo presidente com a estabilidade de preços. Previsões pessimistas não se confirmaram e o índice voltou a apresentar comportamento estável nos anos subsequentes. Do ponto de vista econométrico, esses fatores históricos inerentes a uma análise econômica são complicadores que exigem a criação de dummies para filtragem de efeitos determinísticos, tal como exposto na modelagem econométrica.

O índice dívida/PIB (proxy para política fiscal) também sofre forte influência do ciclo político brasileiro, e, apesar de apresentar certa linearidade, compreende três 
quebras de padrão. Duas delas podem ser explicadas pela eleição de 2002 e pela alteração da política econômica do governo Dilma Rousseff em 2015, enquanto a terceira se deu em 2008, fruto da crise financeira internacional. Por se tratar de um índice com uma relação proporcional entre dívida (numerador) e PIB (denominador), o aumento deste índice não significa necessariamente o aumento de gastos do governo, podendo também significar a queda do $\mathrm{PIB}^{7}$ (Figura 3). Entretanto, conforme assinalado por Pereira et al. (2017) para o caso brasileiro, mesmo com o quadro recessivo seguido de redução na arrecadação, os gastos totais do governo continuaram crescendo a partir do final de 2014. Por fim, a opção pelo índice dívida/PIB como proxy da política fiscal segue o argumento de Cavalcanti e Silva (2010), segundo o qual a omissão da dívida como variável explicativa no modelo empírico gera efeitos (super)estimados viesados, ou seja, considerar explicitamente seu papel na evolução das variáveis fiscais parece fazer diferença ao estimar os efeitos de choques fiscais sobre a atividade econômica.

Com relação à taxa real de câmbio, o comportamento da série apresenta uma volatilidade característica, e os fortes movimentos de depreciação da moeda brasileira podem ser explicados pelo comportamento defensivo do investidor que migra para moedas fortes, como o dólar, em momentos de crise. Mais uma vez, as fortes variações estão associadas ao ciclo político brasileiro a influência do mercado financeiro global. A taxa real de juros, por sua vez, apresenta um comportamento cíclico ${ }^{8}$ acompanhado de uma tendência de queda no período analisado.

A Figura 2 ilustra o índice de preços de ações (Stock) do mercado brasileiro, proxy para o desempenho do mercado acionário nacional.

\footnotetext{
7 Tal problema pode ser resolvido com a utilização parcimoniosa de dummies para filtrar tais ciclos políticos, abordagem da qual o presente trabalho se utiliza.

8 Para lidar com o comportamento cíclico da economia, de forma econométrica, aplica-se logaritmo neperiano nas séries utilizadas para contornar problemas de eventuais quebras estruturais decorrentes de ciclos econômicos e evitar o uso excessivo de dummies passíveis de comprometer os resultados.
} 
p. 69 - Impactos de depreciações cambiais no hiato do produto brasileiro

Figura 2 - Stock, do 4T de 2001 ao 1 T de 2018 (2001 T4 = 100).

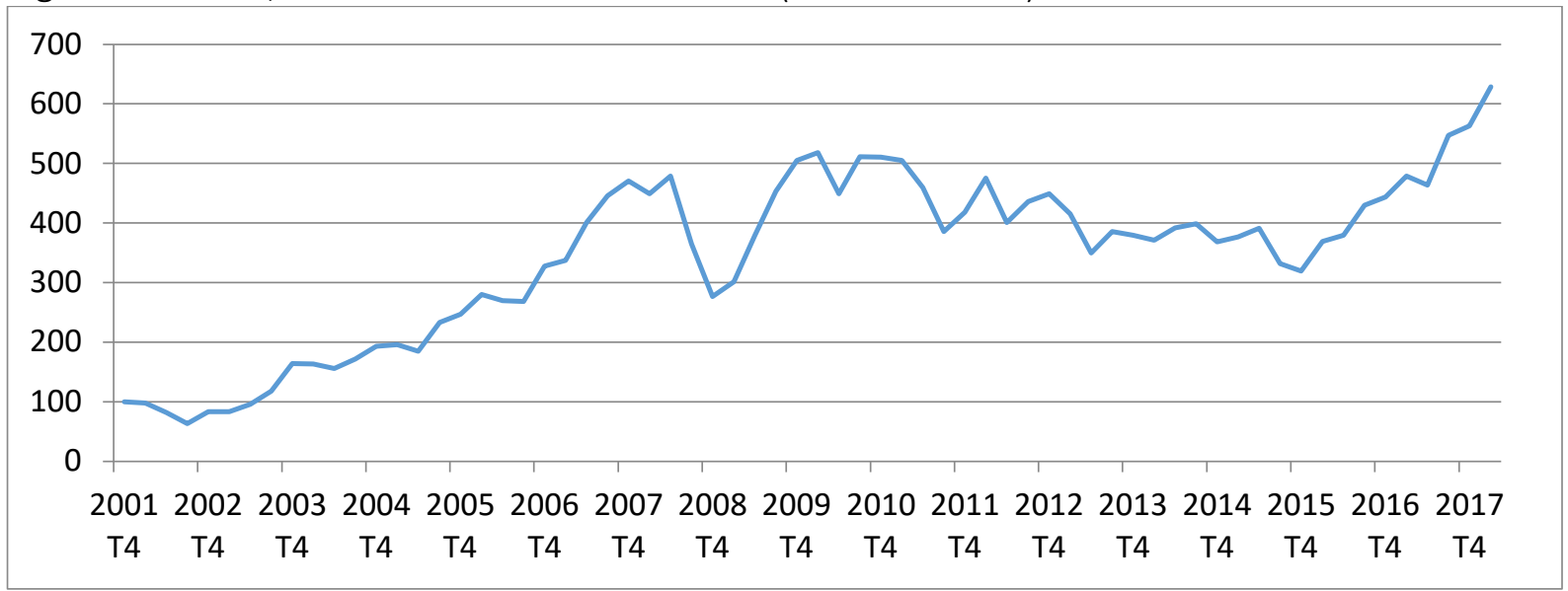

Fonte: International Financial Statistics do Fundo Monetário Internacional.

O comportamento do índice é de crescimento linear desde o seu início, no quarto trimestre de 2001, até a crise de 2008. Após recuperar os níveis pré-crise em 2010, o índice apresenta tendência negativa durante os governos Dilma Rousseff e volta a crescer de forma contínua a partir de 2016.

Por fim, a Figura 3 representa os índices para PIB real e potencial, elaborados a partir dos dados disponibilizados pelo IBGE.

Figura 3 - Índices PIB real e potencial, do 4T de 2001 ao 1T de 2018 (2001 T4 = 100).

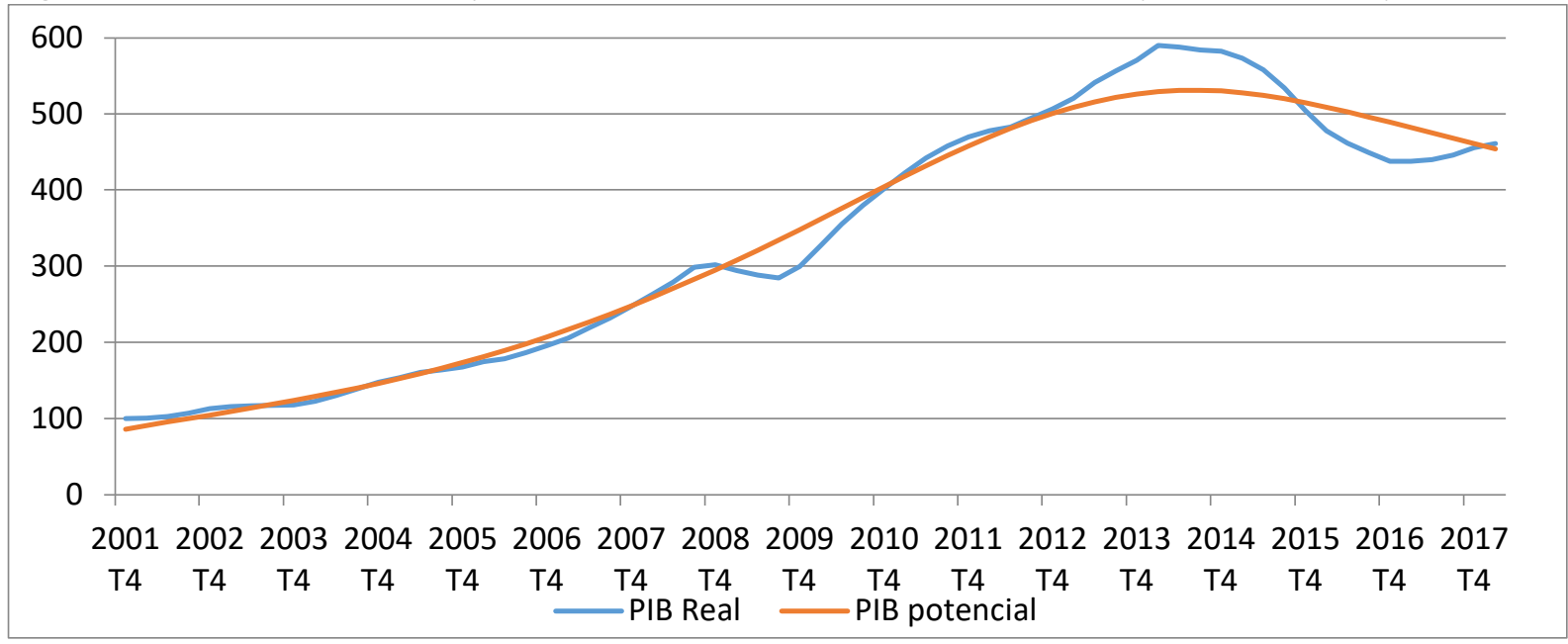

Fonte: Elaboração própria com dados do Instituto Brasileiro de Geografia e Estatística (IBGE).

É possível observar que esta variável possui um comportamento estável, com pequenas oscilações associadas às crises políticas e financeiras. A linha de tendência é interpretada como produto potencial da economia e foi calculada removendo-se a componente cíclica do PIB por meio do filtro de Hodrick-Prescott (HP). A variável 
dependente na análise é o Hiato do Produto, ou seja, a diferença entre o PIB real e o PIB potencial.

Outro ponto passível de destaque refere-se à ocorrência de um período recessivo no triênio 2014-2016. Optou-se por lidar com essa característica particular por meio de filtragem de efeitos determinísticos, isto é, colocando-se uma variável dummy para o intervalo em questão.

\subsection{Modelo de Vetor Autorregressivo}

Utiliza-se neste trabalho o modelo econométrico Vetor Autorregressivo (VAR), mesma metodologia utilizada nas análises macroeconômicas de Peres e Ellery Jr. (2009) e Carvalho, Eduardo e Silva (2013), os quais avaliaram o efeito de impulsos fiscais sobre PIB e mercado de trabalho, respectivamente. Este artigo aborda em segundo plano os mecanismos de política anticíclica, e tem como foco principal compreender como a depreciação cambial impacta o hiato do produto brasileiro no curto prazo. O modelo VAR trata da interação dinâmica entre variáveis e é uma das ferramentas de análise empírica de cenários macroeconômicos, tal como Tomazzia e Meurer (2009) que avaliaram a transmissão da política monetária para o setor industrial.

Segundo Bueno (2008), séries econômicas apresentam comportamento de longo de prazo em comum, o que pode ser constatado visualmente neste trabalho por meio da Figura 01, na qual 4 das 6 variáveis de interesse estão representadas. Tal fato põe sob suspeita a abordagem do modelo VAR em sua forma reduzida, e levanta a necessidade de se avaliar cointegração entre as séries. No entanto, tal análise será preterida em função dos objetivos da análise de curto prazo. Tomazzia e Meurer (2009) justificam que, para modelos autorregressivos com variáveis em primeira diferença, os testes de cointegração e os mecanismos de correção se tornam desnecessários.

Uma segunda justificativa para utilização da metodologia VAR, preterindo a análise de cointegração e consequentemente o modelo de Vetor de Correção de Erros (VECM), se deve ao fato de, segundo Bueno (2008), as variáveis do modelo precisarem ser integradas de mesma ordem, e, conforme será discutido mais adiante, isso não ocorrer na análise de estacionariedade. A variável "Hiato do produto" é estacionária em 
p. 71 - Impactos de depreciações cambiais no hiato do produto brasileiro

nível, não necessitando de diferenciação. Assim, o modelo VAR adequado ao propósito do trabalho segue a equação (5):

$Y_{t}=\varphi_{0}+\sum_{i}^{p} \varphi_{i} Y_{t-1}+G Z_{t}+e_{t}$

O vetor $Y_{t}$ é um vetor $n \times 1$, composto das variáveis do modelo, a priori consideradas todas endógenas, $Z_{t}$ é uma matriz $n \times g$ onde constam as variáveis exógenas ao modelo, e também as dummies determinísticas. Neste trabalho utilizam-se duas dummies com a finalidade de filtrar situações atípicas da economia, principalmente aquelas relacionadas ao ciclo político. A primeira delas, denominada "crise", assume o valor 1 do quarto trimestre de 2008 até o terceiro trimestre de 2009, período da crise imobiliária americana. Essa mesma variável assume o valor unitário também do segundo trimestre de 2014 ao quarto trimestre de 2016, período marcado por intensa crise política no cenário brasileiro. Uma segunda dummy, denominada "expectativa", visa filtrar o efeito que as expectativas da eleição de Luiz Inácio Lula da Silva criaram sobre inflação e estabilidade da moeda ao final de 2002, e assume valor unitário do terceiro trimestre de 2002 ao terceiro trimestre de 2003. Optou-se por separar as dummies determinísticas em duas por entender que a dummy "crise" é mais complexa e envolve maior quantidade de fatores quando comparada à "expectativa". Entende-se também que o uso excessivo de dummies pode distorcer o modelo, portanto o uso desta ferramenta é feito com parcimônia.

O modelo proposto segue a lógica de ordenação das variáveis da mais exógena para a mais endógena, conforme equação (6), e também se ancora no referencial teórico de Hsing (2005).

$$
Y_{t}=\left[\begin{array}{c}
\text { Expectativa de Inflação } \\
\text { Dívida/PIB } \\
\text { Taxa de Câmbio } \\
\text { Stock } \\
\text { Taxa de Juros } \\
\text { Hiato do Produto }
\end{array}\right]
$$


A análise de estacionariedade é feita através dos testes de Dickey-Fuller Aumentado (ADF) e Kwiatkowski Phillips Schmidt Shin (KPSS). No teste ADF a hipótese nula é de que há raiz unitária na série, portanto as mesmas não são estacionárias, enquanto que no teste KPSS a hipótese nula é a de que as séries são estacionárias. Para lidar com problemas relacionados à quebra estrutural, trabalhou-se com as séries loglinearizadas. O lag escolhido para ambos os testes seguiu o critério de informação de Schwartz, o qual resultou em dois lags. Por fim, verificou-se a existência de raiz unitária tanto com tendência quanto sem tendência. Os resultados podem ser observados na Tabela 01 . Os valores $t$ críticos para rejeição ou não rejeição da hipótese nula com $5 \%$ de confiabilidade foram de -2,29 e -3,487 para o teste ADF e de 0,463 e 0,146 para o teste KPSS, considerando as séries sem tendência e com tendência, respectivamente.

Tabela 01 - Teste de Raiz Unitária ADF e KPSS considerando dois lags.

\begin{tabular}{|c|c|c|c|c|}
\hline Variável & $\begin{array}{l}\text { Valores críticos } \\
\text { ADF } \\
\text { Sem tendência }\end{array}$ & $\begin{array}{c}\text { Valores Críticos } \\
\text { KPSS } \\
\text { Sem tendência }\end{array}$ & $\begin{array}{l}\text { Valores críticos } \\
\text { ADF } \\
\text { Com tendência }\end{array}$ & $\begin{array}{c}\text { Valores Críticos } \\
\text { KPSS } \\
\text { Com tendência }\end{array}$ \\
\hline In_expctinf & $-2,329$ & 0,198 & $-2,351$ & 0,207 \\
\hline$\Delta n_{-}$expctinf & $-5,382$ & 0,074 & $-5,330$ & 0,058 \\
\hline In_dvipib & $-1,474$ & 0,786 & $-0,447$ & 0,308 \\
\hline$\Delta$ In_divpib & $-4,617$ & 0,159 & $-5,656$ & 0,371 \\
\hline In_cambio & $-1,700$ & 1,010 & $-1,384$ & 0,469 \\
\hline$\Delta \ln \_$cambio & $-6,139$ & 0,156 & $-6,485$ & 0,037 \\
\hline In_stock & $-2,258$ & 1,151 & $-2,151$ & 0,460 \\
\hline$\Delta \mathrm{ln} \_$stock & $-5,005$ & 0,146 & $-5,378$ & 0,080 \\
\hline In_juros & $-1,852$ & 1,117 & $-2,833$ & 0,244 \\
\hline$\Delta \mathrm{ln} \_$juros & $-4,194$ & 0,066 & $-4,164$ & 0,066 \\
\hline In_pib_hp_c & $-3,357$ & 0,109 & $-3,557$ & 0,109 \\
\hline$\Delta I n \_p i b \_h p \_c$ & - & - & - & - \\
\hline
\end{tabular}

Fonte: Elaboração própria a partir da base de dados.

De acordo com ambos os testes, não se pode rejeitar a hipótese da série não ser estacionária em nível, isto é, da presença de raiz unitária. A exceção se dá no logaritmo neperiano do hiato do produto, representado na tabela como a componente cíclica extraída da série PIB real por meio do filtro de Hodrick-Precott (In_pib_hp_c). Tal resultado, como previamente mencionado, pode ser considerado uma justificativa para utilização do modelo VAR. Os lags utilizados para formulação do vetor autorregressivo seguiram o critério de Schwartz ou o critério BIC com dois lags de defasagem. Dada a 
p. 73 - Impactos de depreciações cambiais no hiato do produto brasileiro

estabilidade do modelo $\operatorname{VAR}_{(2)}$, foram analisadas as funções impulso resposta e a decomposição da variância das variáveis.

\section{RESULTADOS}

Além da análise dos efeitos de choques cambiais sobre o hiato do produto, utilizam-se também as políticas fiscal e monetária como variáveis independentes, as quais são importantes para fins comparativos, de forma a mensurar o efeito de um choque exógeno no câmbio e compará-lo com outros instrumentos tradicionais de política econômica. Optou-se neste trabalho pela análise da função impulso-resposta acumulada das variáveis, apresentada com intervalo de confiança de 95\%, a partir do primeiro período, a qual permite a leitura dos choques na forma de elasticidades e facilita a observação das relações entre as variáveis.

A Figura 4 mostra o efeito de um choque exógeno no câmbio sobre o hiato do produto e as demais variáveis. Para uma depreciação cambial da ordem de 1\%, há um aumento de $0,05 \%$ no hiato do produto em 36 meses. Tal comportamento permite concluir que a depreciação cambial é expansionista, embora de baixa magnitude, para o caso brasileiro, no curto prazo, corroborando os trabalhos de Missio, Schettini e Jayme Jr (2009) e Araújo e Gala (2012), para os quais o produto da economia cresce em consequência de câmbios mais elevados. Por sua vez, os resultados divergem dos trabalhos de Hsing (2005) e An, Kim e Ren (2014), os quais concluíram que depreciações cambiais são contracionistas, no primeiro caso para a Alemanha e no segundo para países da América Latina. 
Figura 4 - Função impulso-resposta acumulada de choque exógeno na taxa real de câmbio sobre as demais variáveis.

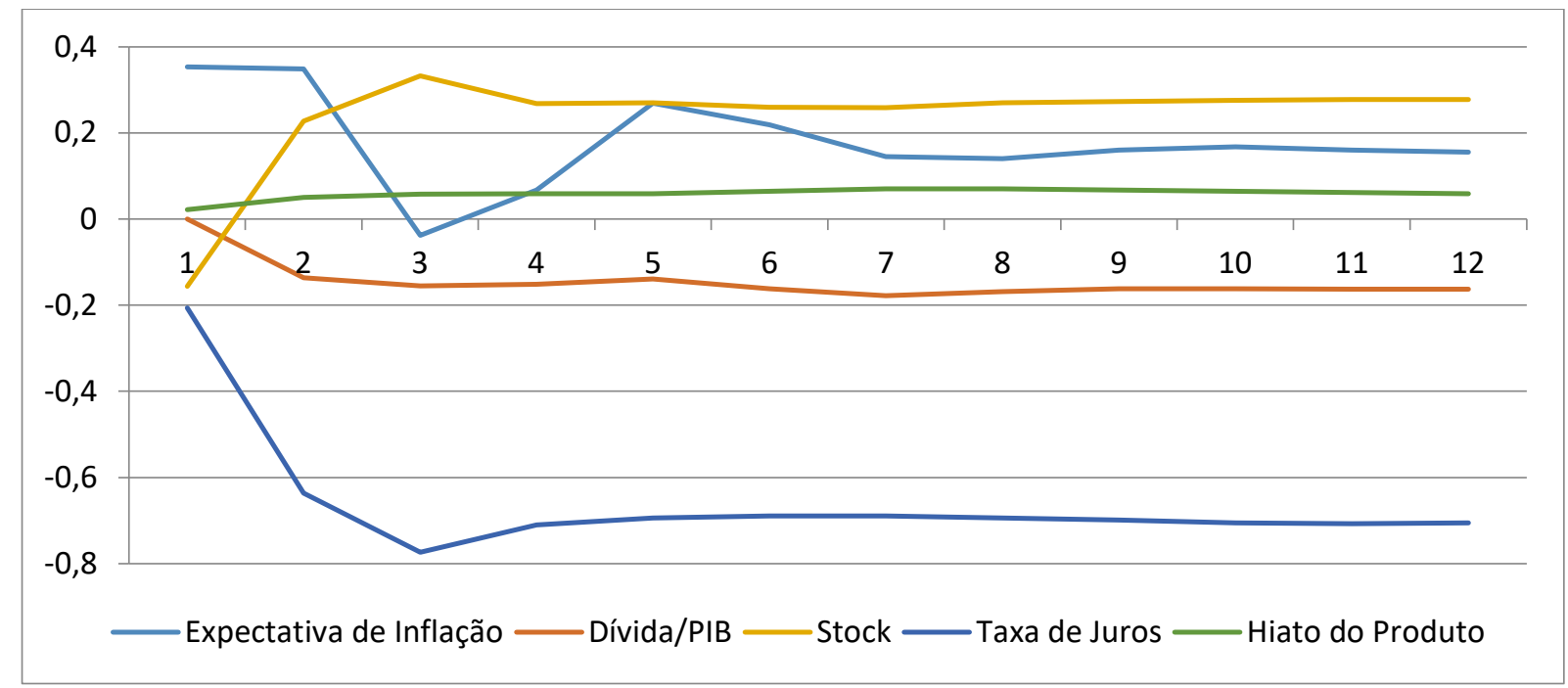

Fonte: Estimação própria a partir da metodologia descrita.

De acordo com a literatura analisada, a depreciação cambial redistribui renda de salários para lucros. A ligeira expansão do hiato do produto pode indicar que a economia brasileira seja profit-led, ou seja, que exista uma relação direta entre maiores participações de lucros na renda doméstica e a demanda agregada. Ainda, é possível supor que os efeitos contracionistas da elevação de custos de insumos importados sejam discretamente compensados pela elevação das exportações domésticas.

Com relação à persistência do choque cambial sobre as demais variáveis, destaca-se a influência negativa sobre as taxas reais de juros e positiva sobre o índice do mercado de ações, esta última diferindo do trabalho de Pereira e Da Silva Chicoli (2016), segundo o qual o valor acionário das firmas é afetado por alterações cambiais através de sua competitividade e também por variações nos valores de seus ativos e passivos denominados em moeda estrangeira. Ainda, a depreciação cambial eleva a expectativa de inflação nos períodos subsequentes ao choque, estabilizando-se em aproximadamente sete períodos. Em termos de elasticidades, para depreciações cambiais da ordem de $1 \%$ há um aumento na expectativa de inflação da ordem de 0,15\% e uma diminuição de aproximadamente 0,02\% na relação dívida/PIB.

A Figura 5 retrata a função impulso-resposta acumulada de um choque exógeno na taxa real de juros sobre as demais variáveis. Observa-se uma relação negativa na 
p. 75 - Impactos de depreciações cambiais no hiato do produto brasileiro

qual uma elevação de $1 \%$ na taxa real de juros teria impacto negativo de $0,39 \%$ no hiato do produto ao final de 12 trimestres.

Figura 5 - Função impulso-resposta acumulada de choque exógeno na taxa real de juros sobre as demais variáveis.

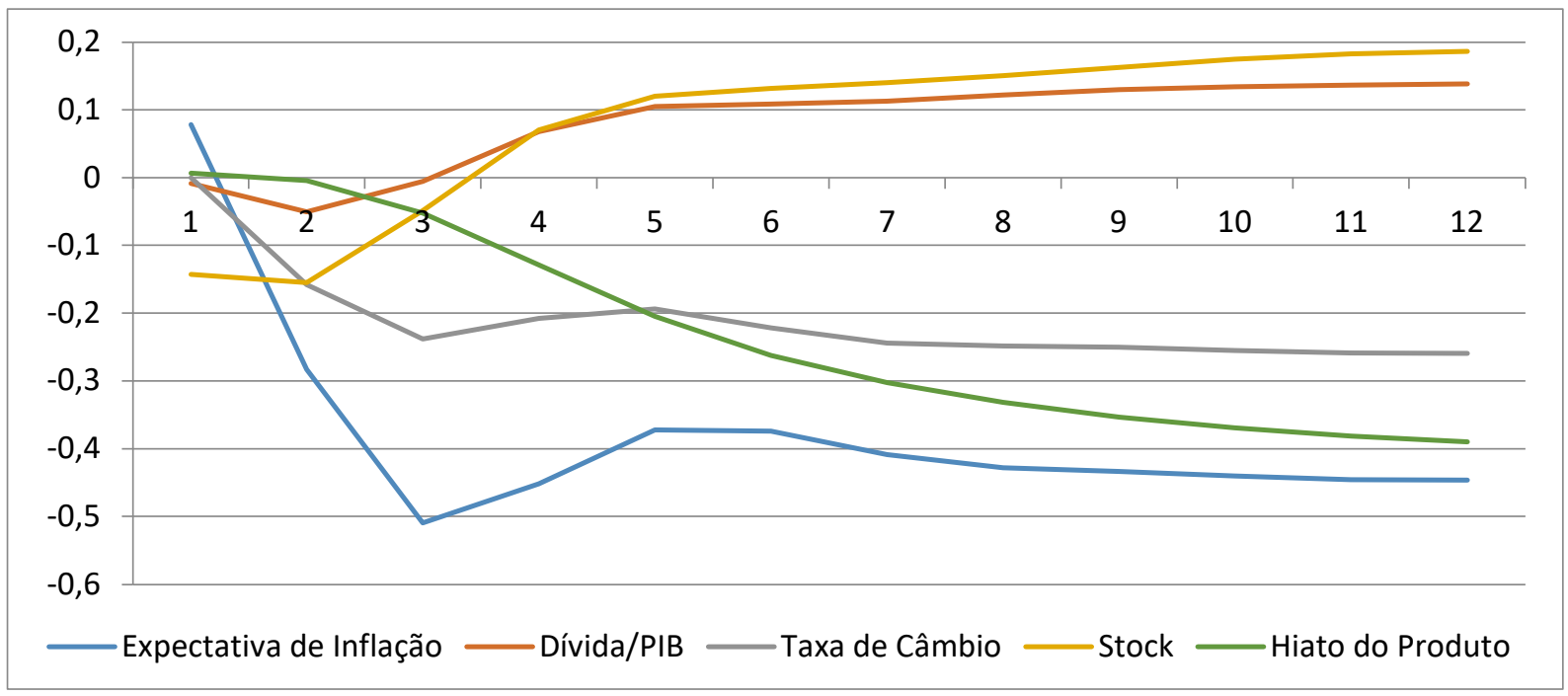

Fonte: Estimação própria a partir da metodologia descrita.

Considerando o impacto da elevação da taxa de juros sobre a expectativa de inflação, o efeito negativo tem maior magnitude quando comparado aos demais. Em termos de elasticidades, para um aumento de $1 \%$ na taxa de juros há uma redução da expectativa da inflação da ordem de 0,45\%. No que se refere à relação dívida/PIB, há um aumento de 0,14\% enquanto a taxa real de câmbio é apreciada em 0,25\%. Há uma transitoriedade detectada no modelo relacionada ao mercado acionário, ou seja, a variável stock é negativa nos primeiros períodos que sucedem o choque, mas no acumulado do período passa a ser positiva, com valor inferior a 0,2\%. Para dados em disposição trimestral, isso significa uma dissipação em nove meses da influência negativa da oscilação da taxa de juros sobre o mercado acionário.

A Figura 6 apresenta o efeito de um choque exógeno na variável dívida/PIB, proxy para política fiscal, sobre as demais variáveis. Avaliando-se através de elasticidades, um aumento de $1 \%$ na relação dívida/PIB traria um aumento mais que proporcional do hiato do produto, da ordem de 2,3\%. Há, no entanto, os efeitos indesejados sobre expectativa de inflação e taxa de juros, as quais aumentariam na ordem de 1,9\% e 2,2\%, respectivamente. Ainda, a taxa de câmbio depreciaria em 0,7\%, enquanto que a variável stock cairia em torno de 2,1\%. 
Figura 6 - Função impulso-resposta acumulada de choque exógeno na relação dívida/PIB sobre as demais variáveis.

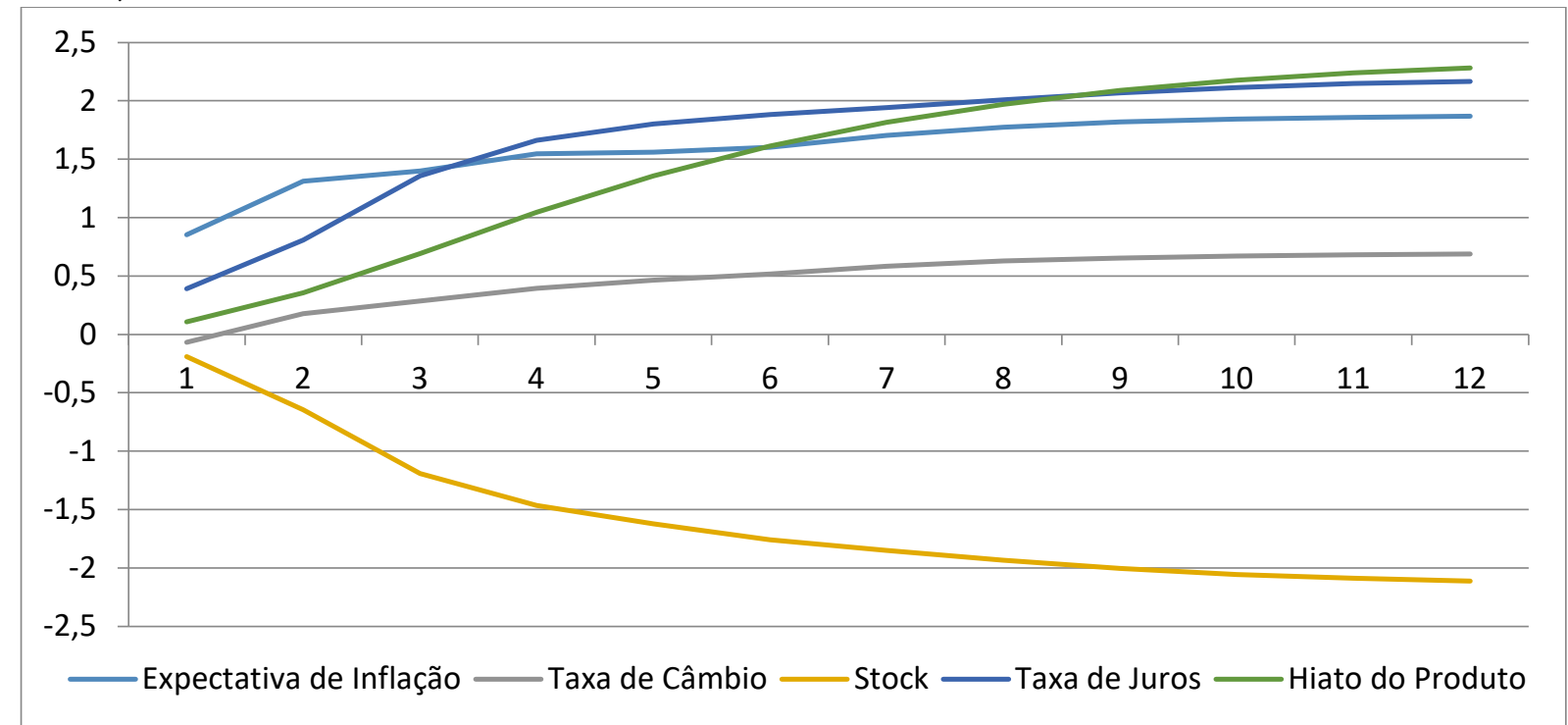

Fonte: Estimação própria a partir da metodologia descrita.

Comparando os resultados das Figuras 4, 5 e 6, o choque na variável dívida/PIB é o que apresenta maior magnitude quanto ao impacto no hiato do produto, ou seja, é aquele que tem a maior capacidade de estimular o mesmo no curto prazo. Contudo, as também fortes elevações de expectativa de inflação e taxa de juros são passíveis de atenuar esse impacto nos períodos subsequentes. De forma complementar, é possível sugerir um movimento defensivo do mercado acionário com a elevação do indicador dívida/PIB, isto é, os agentes migram do mercado acionário provocando apreciação cambial e elevação dos juros reais. Quando comparado ao choque da taxa de juros já descrito, este resultado mostra uma maior sensibilidade dos agentes ao comportamento dos gastos do governo.

A Tabela 2, abaixo, exibe a decomposição da variância do hiato do produto.

Pode-se observar que o hiato do produto depende essencialmente, nos primeiros períodos, de si próprio, da taxa real de juros e da expectativa de inflação. Nos períodos subsequentes há um decréscimo da importância das variáveis mencionadas, e, num movimento contrário, a variável dívida/PIB, a qual inicialmente explica pouco mais de $3 \%$ do hiato do produto, passa a assumir valores superiores a $50 \%$ a partir do sétimo período. No último período de análise, as variáveis dívida/PIB e hiato do produto são responsáveis, conjuntamente, por quase 91\% da variância em questão. Nesse sentido, 
p. 77 - Impactos de depreciações cambiais no hiato do produto brasileiro

reafirmando os resultados expostos na Figura 6, é possível destacar a importância da política fiscal como instrumento de política econômica no curto prazo. Por outro lado, expectativa de inflação e taxa de juros explicam em torno de $4 \%$ e $1,8 \%$ do hiato do produto, respectivamente, ao final de 12 períodos.

Tabela 2 - Decomposição da variância do Hiato do Produto.

\begin{tabular}{ccccccc}
\hline Período & $\begin{array}{c}\text { Expectativa de } \\
\text { Inflação }\end{array}$ & Divida/PIB & $\begin{array}{c}\text { Taxa de } \\
\text { Câmbio }\end{array}$ & Stock & Taxa de Juros & $\begin{array}{c}\text { Hiato do } \\
\text { Produto }\end{array}$ \\
\hline 1 & $8,14 \%$ & $3,29 \%$ & $0,01 \%$ & $2,56 \%$ & $8,44 \%$ & $77,57 \%$ \\
2 & $10,90 \%$ & $14,27 \%$ & $0,59 \%$ & $3,39 \%$ & $8,02 \%$ & $62,83 \%$ \\
3 & $10,95 \%$ & $27,90 \%$ & $0,55 \%$ & $2,27 \%$ & $5,41 \%$ & $52,92 \%$ \\
4 & $8,03 \%$ & $38,51 \%$ & $0,65 \%$ & $2,32 \%$ & $3,37 \%$ & $47,11 \%$ \\
5 & $5,87 \%$ & $44,95 \%$ & $0,81 \%$ & $2,41 \%$ & $2,49 \%$ & $43,47 \%$ \\
6 & $4,88 \%$ & $48,29 \%$ & $0,88 \%$ & $2,33 \%$ & $2,18 \%$ & $41,44 \%$ \\
7 & $4,43 \%$ & $50,04 \%$ & $0,93 \%$ & $2,27 \%$ & $2,02 \%$ & $40,31 \%$ \\
8 & $4,21 \%$ & $50,98 \%$ & $0,96 \%$ & $2,26 \%$ & $1,92 \%$ & $39,67 \%$ \\
9 & $4,09 \%$ & $51,51 \%$ & $0,97 \%$ & $2,26 \%$ & $1,87 \%$ & $39,30 \%$ \\
10 & $4,02 \%$ & $51,83 \%$ & $0,96 \%$ & $2,27 \%$ & $1,84 \%$ & $39,07 \%$ \\
12 & $3,99 \%$ & $52,01 \%$ & $0,96 \%$ & $2,27 \%$ & $1,83 \%$ & $38,93 \%$ \\
\hline
\end{tabular}

Fonte: Estimação própria a partir da metodologia descrita.

Objeto principal de análise nesse trabalho, a taxa de câmbio tem participação bastante tímida na explicação do hiato do produto, partindo de $0,01 \%$ no primeiro período para $0,96 \%$ nos últimos três períodos, ou seja, não se mostra tão expressiva frente às demais variáveis do modelo. Corroborando os resultados das figuras 4, 5 e 6, as possibilidades da taxa real de câmbio de impactar o nível de atividade econômica no curto prazo, quando comparadas às tradicionais políticas fiscal e monetária, são bastante limitadas.

\section{CONCLUSÕES}

Neste trabalho, foram analisados os efeitos de depreciações na taxa real de câmbio sobre o hiato do produto no Brasil, utilizando dados trimestrais do final de 2001 ao início de 2018. Apesar da existência de vasta literatura internacional sobre o tema, os resultados não são conclusivos e focam especialmente em relações de longo prazo, enquanto o presente trabalho avalia os efeitos de curto prazo de depreciações cambiais sobre o hiato do produto, levando também em conta o papel das políticas monetária e fiscal a fim de se enriquecer a análise. 
Os resultados apontam que a depreciação cambial no curto prazo é expansionista para o caso brasileiro no período analisado, embora com baixa magnitude, confirmando o mecanismo de propagação apontado por Bahmani-Oskooee e Miteza (2003), no qual o aumento de preço dos importados torna a produção doméstica mais competitiva, estimulando a produção interna e as exportações. Ainda, demonstrou-se que o hiato do produto brasileiro é explicado principalmente por ele mesmo, e pelas variáveis dívida/PIB e expectativa de inflação, tendo o câmbio pouco poder explicativo.

Num contexto de curto prazo, no qual o espaço para aplicação de políticas econômicas usualmente é reduzido, os efeitos discretos da política cambial sobre o hiato do produto sugerem pela utilização das tradicionais políticas fiscal e monetária em especial a política fiscal, a qual tem efeitos positivos de maior magnitude sobre o hiato do produto - quando da necessidade de estímulos rápidos para a atividade econômica. É importante ressaltar que tal cenário não tira da política cambial a sua relevância, mas indica que os principais impactos expansionistas decorrentes de depreciações cambiais, conforme Gala e Libânio (2008) e Araújo e Gala (2012), ocorrem no longo prazo para a economia brasileira.

\section{REFERÊNCIAS BIBLIOGRÁFICAS}

AGÉNOR, P.-R. Output, devaluation and the real exchange rate in developing countries. Weltwirtschaftliches Archiv, v. 127, n. 1, p. 18-41, 1991.

AN, L.; KIM, G.; REN, X. Is devaluation expansionary or contractionary: Evidence based on vector autoregression with sign restrictions. Journal of Asian Economics, v. 34, p. 2741, 2014.

ARAÚJO, E.; GALA, P. Regimes de crescimento econômico no Brasil: evidências empíricas e implicações de política. Estudos Avançados, v. 26, n. 75, p. 41-56, 2012.

BAHMANI-OSKOOEE, M.; MITEZA, I. Are devaluations expansionary or contractionary? A survey article. Economic Issues Journal Articles, v. 8, n. 2, p. 1-28, 2003.

BHADURI, A.; MARGLIN, S. Unemployment and the real wage: the economic basis for contesting political ideologies. Cambridge Journal of Economic, v. 14, p. 375-393, 1990. 
p. 79 - Impactos de depreciações cambiais no hiato do produto brasileiro

BUENO, R. D. L. S. Econometria de séries temporais. Cengage Learning: São Paulo, 2008. CARVALHO, D. B.; EDUARDO, M.; SILVA, E. M. Efeitos dos Choques Fiscais sobre o Mercado de Trabalho Brasileiro. Revista Brasileira de Economia, v. 67, n. 2, p. 177-200, 2013.

CAVALCANTI, M. A. F. H.; SILVA, N. L. C. Dívida pública, política fiscal e nível de atividade: uma abordagem VAR para o Brasil no período 1995-2008. Economia Aplicada, v. 14, n. 4, p. 391-418, 2010.

COOPER, R.N. Currency Devaluation in Developing Countries. Essays in International Finance. Princeton University, n. 86,1971.

DA SILVA, G. J. C.; CORREIA, F. M.; SANTOLIN, R. S. Fluxo de capitais e crescimento econômico de longo prazo: teoria, modelo e evidências recentes para as economias emergentes. Revista de Economia do Centro-Oeste, v. 1, n. 1, p. 2-25, 2015.

DE PAULA, L. F. R.; ALVES JR., A. J. External Financial Fragility and the 1998-99 Brazilian Currency Crisis. Journal of Post Keynesian Economics, v. 22, n. 4, p. 589-618, 2000.

DÍAZ-ALEJANDRO, C. F. A Note on the Impact of Devaluation and the Redistributive Effect. The Journal of Political Economy, p. 577-580, 1963.

DO NASCIMENTO, B. R. V. et al. Relação do emprego, da renda e das variáveis políticomonetárias com as decisões de modalidades de crédito. Revista de Economia do CentroOeste, v. 3, n. 2, p. 38-54, 2017.

DORNBUSCH, R. et al. Currency Crises and Collapses. Brookings Papers on Economic Activity, v. 1995, n. 2, p. 219, 1995.

EDWARDS, S. Are Devaluations Contractionary? The Review of Economics and Statistics, v. 68, n. 3, p. 501-508, 1986.

FRANKEL, J. A.; ROSE, A. K. Currency crashes in emerging markets: An empirical treatment. Journal of International Economics, v. 41, p. 351-366, 1996.

GALA, P.; LIBÂNIO, G. A. Efeitos da apreciação cambial nos salários, lucros, consumo, investimento, poupança e produtividade: uma perspectiva de curto e longo prazo. In: XXXVI Encontro Nacional de Economia, 2008.

HSING, Y. Application of the IS-MP-IA model to the German economy and policy implications. Economics Bulletin, v. 15, n. 5, p. 1-10, 2005. 
KAMIN, S. B.; ROGERS, J. H. Output and the real exchange rate in developing countries: An application to Mexico. Journal of Development Economics, v. 61, n. 1, p. 85-109, 2000.

KRUGMAN, P.; TAYLOR, L. Contractionary effects of devaluation. Journal of International Economics, v. 8, n. 3, p. 445-456, 1978.

LIZONDO, J. S.; MONTIEL, P. J. Contractionary devaluation in developing countries: an analytical overview. Staff Papers, v. 36, n. 1, p. 182-227, 1989.

MISSIO, F; OREIRO, J. L.; JAYME JR. F. G. Câmbio, crescimento e heterogeneidade produtiva num modelo keynesiano-estruturalista. Texto para Discussão 413, UFMG/Cedeplar, 2010.

MISSIO, F. J.; SCHETTINI, B.; JAYME JR. F. G. Câmbio e crescimento: teoria e implicações de política econômica, In: Encontro Internacional da Associação Keynesiana Brasileira, Porto Alegre: AKB, 2009.

NASSIF, A.; FEIJÓ, C.; ARAÚJO, E. Overvaluation trend of the Brazilian currency in the 2000s: empirical estimation. Revista de Economia Política, v. 35, n. 1, p. 3-27, 2015.

PEREIRA, J. R. de L. M.; DA SILVA CHICOLI, R. Como Alterações na Taxa de Câmbio Afetam o Retorno do Índice Ibovespa. Finanças Públicas: o Difícil Caminho das Metas Fiscais, p. 44, 2016.

PEREIRA, H. C. I. et al. Uma perspectiva crítica do novo regime fiscal para a dinâmica de curto e longo prazo da economia brasileira. Revista de Economia Do Centro-Oeste, v. 3, n. 1, p. 51-69, 2017.

PERES, M. A.; ELLERY, R. Efeitos dinâmicos dos choques fiscais do governo central no PIB. Pesquisa e Planejamento Econômico, v. 39, n. 2, p.159-206, 2009.

ROMER, D. Keynesian Macroeconomics without the LM Curve. Journal of Economic Perspectives, v. 14, n. 2, p. 149-170, 2000.

SCHWARTSMAN, A. A crise cambial e o ajuste fiscal. Revista de Economia Política, v. 19, n. 1, p. 5-29, 1999.

TOMAZZIA, E. C.; MEURER, R. O mecanismo de transmissão da política monetária no Brasil: uma análise em VAR por setor industrial. Economia Aplicada, v. 13, n. 4, p. 371398, 2009. 